\title{
A EXPLOSÃO DO OLHAR: DO TABACO NOS ARAWA DO RIO PURUS*
}

\author{
Miguel Aparicio
}

El tabaco era antes gente. Le gustaban los cuentos y por eso vivía siempre arrimado a la pared de las casas, para escuchar cómo echaban cuentos. Cada vez que oía hablar en una casa, venía, se paraba en la pared y escuchaba. Por eso la Madre hizo que creciera siempre alrededor de las casas, cerquita de la pared. Allá puede escuchar

(Reichel-Dolmatoff, Los Kogi, 1952).

Em múltiplos cenários das terras baixas sul-americanas, o tabaco aparece como a planta mais estreitamente vinculada às experiências de comunicação entre humanos e não humanos, assim como aos processos de metamorfose dos corpos. O controle, o uso e o domínio desta planta fazem parte, ainda, das competências primordiais da atividade xamânica. Numerosas etnografias destacam a relevância do tabaco nas concepções indígenas da Amazônia $^{1}$, de tal forma que parece pertinente afirmar que esta planta é frequentemente pensada como constituinte da condição de "humanos verdadeiros". O propósito destas páginas é avançar na compreensão das ideias e das práticas a ela relacionadas entre os coletivos Arawa, a partir da maneira com que os Suruwaha pensam (com) o tabaco, e seguindo o itinerário traçado por ele entre os Banawa, os Deni e outros coletivos Arawa, todos eles habitantes das terras ocidentais no vale do rio Purus. Os Suruwaha, os Banawa e os Deni - com os quais desenvolvi meu trabalho de campo $^{2}$ - fazem parte da família linguística Arawa junto com os Paumari, Jarawara, Jamamadi orientais, Hi Merimã, Kulina, Kamadeni e Jamamadi ocidentais. ${ }^{3}$ Com exceção dos Kulina, espalhados do Ucayali até a foz do rio Juruá, todos eles habitam as terras do interflúvio Purus-Juruá. A partir da minha experiência etnográfica, este texto transita através da mitologia do tabaco nos coletivos arawa, em diálogo com as Mitológicas de Lévi-Strauss e com as etnografias recentemente produzidas por outros autores na região. ${ }^{4}$

Dou uma atenção especial, portanto, às suas mitologias, aderindo à convicção lévistraussiana de que "os mitos se pensam entre si" (CC 31), ${ }^{5} \mathrm{e}$ percebendo que, assim como o próprio tabaco, eles circulam constantemente 
na rede de pessoas e aldeias na qual os Arawa se movimentam. ${ }^{6}$ Ensaio desta forma um percurso entre a etnografia e a mitologia, propiciado pela presença marcante do tabaco tanto no cotidiano destes grupos indígenas quanto nos momentos coletivos em que esta "planta de poder" é consumida em círculos de conversa que abrem espaço à narração dos mitos.

Sempre tive a impressão de que os Suruwaha mantinham uma espécie de ambiguidade nas suas ideias e práticas sobre o tabaco, kumadi: uma oscilação entre o seu caráter perigoso, venenoso, confuso (danuzy) e o caráter benevolente e agradável (kahy) que ele também possui. Lévi-Strauss, em Do mel às cinzas, já tinha percebido este paradoxo. Caracterizou o tabaco como ultraculinário em oposição ao mel - infraculinário e também ambíguo - e constatou como na mitologia sul-americana desenvolve relações de transformação sob a forma de quiasmas. O tabaco, contraditoriamente "bom" e "ruim", apresenta uma clivagem em função do modo de preparo para o consumo (queimado ou molhado) e em função do seu uso cultural: profano ou sagrado ( $M C$ 371), alimento supremo ou veneno extremo, estimulante ou narcótico (MC 60), manifestando o "cromatismo genuíno"7 que há entre estes aspectos.

Nas roças suruwaha, junto à mandioca, os abacaxis, o caju e o milho, crescem as plantas de tabaco e de timbó: nos roçados há, portanto, alimentos e antialimentos. A vida cotidiana dos Suruwaha se torna mais agradável com o kumadi, o tabaco em pó temperado com cinzas de cupuí ${ }^{8}$ e inalado através do osso da asa do gavião-real, do urubu-rei ou do mutum. Ele dá inspiração na caça e resistência nos momentos de esforço físico, como na derrubada de um roçado ou no retorno de uma pescaria de timbó ao carregar os cestos cheios de matrinxãs moqueadas. Afasta a preguiça e a indolência (zama kahyzynaxu) das pessoas que permanecem inativas em casa, e estimula o ânimo daqueles que sofrem dores ou mal-estar no corpo.

As jornadas na casa dos Suruwaha finalizam sempre com rodadas de conversa em que uma pessoa oferece tabaco às demais ao redor da sua fogueira: enquanto todos inalam, comentam-se as atividades mais destacadas do dia, discutem-se os assuntos que preocupam os adultos, ou simplesmente deixa-se à solta o bom humor em piadas divertidas e imitações brincalhonas do comportamento de alguém presente ou ausente. O tabaco nestas rodadas noturnas inspira os mais velhos, que contam os mitos aos jovens e crianças, atentos às suas narrações. Nunca pode ser sovinado (tukwazawanaxu), e usualmente é inalado de forma compartilhada: as pessoas colocam o tabaco - conservado dentro do bico de um tucano - na palma da mão de um companheiro, sobre a qual o inalam; na sequência, as posições se invertem. ${ }^{9}$ Outra maneira habitual de consumi-lo consiste em assoprar nas narinas do 
parceiro certa quantidade de tabaco, utilizando um osso de ave (kuwasi), para depois deixar que ele insufle o tabaco nas próprias narinas, ou seja, o tabaco se consome frequentemente de maneira recíproca, junto aos semelhantes, as pessoas jadawa.

Em situações de raiva e de conflito, é comum que o tabaco insuflado tranquilize o coração da pessoa alterada. Há momentos em que a pessoa irritada grita pedindo que alguém assopre com vigor doses intensas de tabaco: aruwa wahunxuwa! ("assopra-me [tabaco]!") - sabe que a embriaguez lhe devolverá o comportamento correto de pessoa, jadawa. É possível ainda que alguém imponha essa overdose de tabaco a quem irrompe na casa com uma conduta agressiva e violenta, insuflando tabaco com força, numa espécie de "ataque apaziguador", com um sopro idêntico ao que exigem os dardos da zarabatana ao disparar. ${ }^{10} \mathrm{O}$ tabaco acalma, serena, traz harmonia na vida doméstica. ${ }^{11}$

Dizem os Suruwaha que, quando a pessoa sente a embriaguez do tabaco, "os olhos explodem" (zubi batanari) e os xamãs se tornam capazes de capturar as músicas dos espíritos-cantores, os kurimia. Assim, por exemplo, Uhuzai contava que "Birikahywy sabia cantar muito bem, era xamã e via os espíritos kurimia quando ficava embriagado pelo tabaco. Um xamã jukihidawa insuflou tabaco em Birikahywy, que sentiu a dor do tabaco. Seus olhos ficaram confusos, entrou debaixo da terra e viu muitos kurimia. ${ }^{12}$ Voou alto, igual a um pássaro, viu os kurimia e cantou" (Fank \& Porta 1996:53). O excesso no consumo do tabaco possibilita o trânsito para a socialidade liminar que os xamãs vivenciam. A linguagem dos cantos apropriados dos espíritos kurimia pelos xamãs - considerados "capturadores dos espíritos-cantores", kurimia agy - descreve os mundos confusos onde habitam os não humanos jadawasu. A embriaguez do tabaco (muwy) deixa os corpos instáveis, altera os sentidos e faz a pessoa circular no limiar de outros mundos, colocando-a numa posição de comunicação com o invisível e, ao mesmo tempo, de perigo de ser capturada.

Se o tabaco está presente nos códigos da cordialidade, ele também faz parte da linguagem da hostilidade e da ameaça, como comentei acima sobre os episódios de raiva. Os xamãs, que fortalecem pelo excesso de tabaco sua capacidade de conectar-se com outros sujeitos do universo, podem também através dele transmitir seu feitiço de morte, mazaru. Aqui se manifesta de novo o paradoxal poder desta planta: da mesma maneira que os xamãs costumam transmitir seu poder iniwa através de recorrentes quantidades de tabaco insufladas aos iniciantes, eles podem assoprar através dele os dardos invisíveis que carregam o feitiço. As pontas dos dedos dos xamãs embriagados pelo tabaco concentram, da mesma forma, sua força perigosa, pois "o feitiço gosta da embriaguez do tabaco" (kumadi muwini mazaru kahy). 
Para avançar na compreensão dos elementos próprios da relação dos "humanos verdadeiros" com o tabaco que a descrição etnográfica possibilitou até agora, torna-se pertinente analisar o sistema de transformação de mitos dos coletivos Arawa. Os mitos nos permitem discernir assim alguns eixos centrais da concepção nativa, no paradoxal movimento detectado por Lévi-Strauss: "Não pretendemos, portanto, mostrar como os homens pensam nos mitos, mas como os mitos se pensam nos homens, e à sua revelia" (CC 31). Como já foi apontado, as narrativas aparecem com mais vigor precisamente nas rodadas noturnas, nas quais o tabaco e os mitos circulam abertamente entre as pessoas jadawa.

\section{O tabaco nos mitos}

Na análise da mitologia ameríndia do mel e do tabaco desenvolvida em Do mel às cinzas, encontramos um movimento regressivo, "da cultura à natureza", avesso ao movimento progressivo próprio da passagem "da natureza à cultura" que emerge em O cru e o cozido, e que segue um itinerário que "contorna, por assim dizer, a mitologia sul-americana por detrás" (MC 219). De maneira análoga à concepção dos Suruwaha, que descrevem os mundos não humanos (aos quais o tabaco dá acesso) como mundos incomensuráveis, difíceis e "confusos" (danuzy), Lévi-Strauss adverte neste fluxo uma "marcha universal em direção à confusão, que é também uma queda em direção à natureza" (MC 241). Mais ainda: o tabaco restabelece a comunicação entre o homem e o sobrenatural, tal como expressa o próprio Lévi-Strauss:

sem o tabaco que a mantém estendida em direção ao sobrenatural, a cultura reduzida a si mesma só pode flutuar indecisa, entre um e outro lado da natureza. Decorrido certo tempo, seu impulso se amortece e a própria inércia a imobiliza no único ponto em que a natureza e a cultura se encontram (MC 242).

Este intervalo é precisamente o âmbito em que opera o xamanismo, um âmbito de equivocidade e de tensão regressiva

[n]o elemento do cromatismo crepuscular céu-terra (viagem xamânica), do fundo universalmente humano de todos os seres, e de uma tecnologia das drogas (tabaco) que embaralha radicalmente a distinção entre natureza e cultura, ao definir uma província da sobrenatureza, isto é, da natureza pensada enquanto cultura (Viveiros de Castro 2008:114). 
Os Suruwaha descrevem, de fato, essas experiências de "embaralhamento" e afirmam que a embriaguez causada pelo tabaco provoca nas pessoas uma sensação de alteração das distâncias, como se as coisas se aproximassem e se distanciassem simultaneamente da pessoa inebriada. Eles falam de "caminhos elásticos" (agi duwari) que os xamãs percorrem para alcançar o mundo dos espíritos, em um itinerário que contrasta com a rigidez dos "caminhos duros" (agi hixa) onde os humanos transitam cotidianamente.

\section{Da origem do tabaco}

Transitando na terra redonda da mitologia ( $M C$ 9), os Banawa e os Paumari, muito próximos dos Suruwaha, ${ }^{13}$ apresentam suas próprias versões sobre a origem do tabaco. Não há um mito suruwaha sobre a origem do tabaco; porém, seguindo a pauta que Lévi-Strauss propõe na Abertura das Mitológicas, é "legítimo, portanto, escolher como ponto de partida qualquer representante do grupo" (CC 20) de transformação e, assim, adentrar a mitologia associada ao tabaco entre os Arawa com base na análise mitológica de Lévi-Strauss, de modo a discernir algumas de suas propriedades centrais a partir das transformações entre as versões de um mesmo mito.

\section{Mowewawa e a origem do tabaco (Banawa) ${ }^{14}$}

Havia uma mulher que gostava muito de agradar as crianças, era carinhosa e queria muito ter um filho, mas ela nunca conseguiu engravidar. As mulheres debochavam dela, jogando no seu corpo os umbigos dos ouriços de castanha. Todas as mulheres da aldeia zombavam dela dessa maneira.

As mulheres percorriam o varadouro de um castanhal quando encontraram um ouriço grande. Olharam o ouriço e perceberam que ele balançava sozinho. As mulheres o levantaram, viram que era pesado, o quebraram com cuidado e se surpreenderam ao ouvir uma criança que chorava dentro dele. Havia uma criança dentro do ouriço e lhe puseram o nome de Mowewawa. As pessoas pensaram que Mowewawa era filho daquela mulher que gostava de agradar as crianças, que queria engravidar e de quem as mulheres zombavam jogando os umbigos dos ouriços de castanha.

Naquele tempo havia três aldeias: uma mais distante, outra que ficava mais perto dos castanhais, e a última aldeia, onde morava o xamã. O xamã caminhava pelo varadouro com a sua esposa. Onde ela urinava, surgia uma planta de tabaco. Urinava de novo, e crescia o tabaco. A mulher, ao perceber isso, disse ao xamã, seu esposo: "Olha isso, onde eu urino cresce um pé de tabaco!". O xamã foi conversar com as folhas, a planta de tabaco disse: "Quando você quiser 
conversar comigo, triture bem as folhas e misture-as com as cinzas do cupuí, você faz o rapé e inala". E o xamã começou a fazer rapé e a conversar com um velho xamã que tinha morrido. Este xamã falou sobre o ouriço de castanha onde estava Mowewawa, a quem as mulheres encontraram quando estavam andando no castanhal. É por isso que, se alguém jogar o bico de um ouriço de castanha numa mulher grávida, a criança com certeza vai morrer: a mãe perderá o menino.

\section{Kahaso e a origem do tabaco (Paumari) ${ }^{15}$}

Kahaso era o único homem solteiro [de sete irmãos]. Seus irmãos tinham fabricado magicamente mulheres tocando árvores e cestos. À noite, os irmãos foram caçar e deixaram Kahaso sozinho com as mulheres, pois ele não caçava devido às feridas que tinha. Um dia ele pediu à mulher de seu irmão mais velho que o acompanhasse ao mato para fazer suas necessidades. Lá ele se transformou num jovem belo e transou com ela. No dia seguinte, ele fez o mesmo com mulher do segundo irmão, e assim por diante durante seis noites seguidas. Na sétima noite, quis tomar a primeira mulher, mas ela recusou dizendo que ele tinha enganado a todos. Seu irmão mais velho tinha se feito passar pela sua esposa. Ao chegarem à mata, ele o desmascarou e o obrigou a masturbar-se diante dele. Do seu esperma nasceram as plantas de tabaco.

Os mitos banawa e paumari sobre a origem do tabaco constituem um grupo de transformação, no qual é possível observar as seguintes relações entre os termos: uma mulher (casada) que não engravida do marido: urina (líquido infértil) :: um jovem (solteiro) que faz sexo com as cunhadas: esperma (líquido fértil, no entanto infértil na masturbação). Ou seja, duas pessoas que podemos caracterizar como portadoras de "anomalias da fertilidade" produzem "líquidos inférteis" (a urina da mulher e o esperma do jovem que se masturba) que se transformam na planta do tabaco. Conectando as duas versões, emerge um grupo de Klein ${ }^{16}$ a partir dos termos: a esposa que não engravida do marido (x), o jovem que faz sexo com muitas cunhadas (-x), o esperma do jovem $(1 / \mathrm{x})$, a urina da esposa $(-1 / \mathrm{x})$, conforme o expressa $\mathrm{o}$ gráfico a seguir.

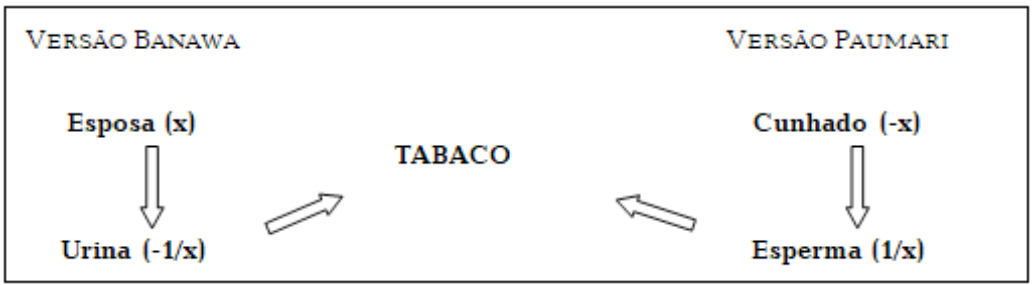


As transformações deste mito não terminam por aqui. As versões banawa e paumari nos levam ao "Rondó do caititu", seção de O cru e o cozido (CC 110 ss.), no qual Lévi-Strauss identifica um metassistema mitológico que demonstra o isomorfismo entre os mitos de origem dos queixadas e caititus e os mitos de origem da culinária. Os mitos de origem do tabaco conectam-se com este metassistema, mostrando como "o tabaco opera a disjunção na família humana" (CC 129), ao separar homens e porcos-do-mato, e ao desempenhar um papel mediador entre a terra e o céu. Parece-me pertinente ampliar as simetrias que Lévi-Strauss encontra ao comparar os mitos bororo e os mitos do Chaco sobre a origem do tabaco (respectivamente, M23-24 e M26) com as versões banawa e paumari que acabei de apresentar. Recorro à seguinte tabela sintagmática/paradigmática, estendendo o procedimento analítico desenvolvido em CC 132-133. ${ }^{17}$

1

\begin{tabular}{|l|l|l|l|l|}
\hline $\begin{array}{l}\text { M23, M24 } \\
\text { (Chaco) }\end{array}$ & $\begin{array}{l}\text { Um marido } \\
(\triangle \text {, aliança) }\end{array}$ & $\begin{array}{l}\text { tem uma esposa } \\
\text { onça }\end{array}$ & $\begin{array}{l}\text { destruidora } \\
\text { por via oral }\end{array}$ & $\begin{array}{l}\text { de um marido que } \\
\text { sobe no alto de uma } \\
\text { árvore. }\end{array}$ \\
\hline M26 (Bororo) & $\begin{array}{l}\text { Uma mãe } \\
(\triangle \text {, filiação) }\end{array}$ & tem um filho cobra & $\begin{array}{l}\text { protetora por } \\
\text { via vaginal }\end{array}$ & $\begin{array}{l}\text { de um filho que } \\
\text { sobe no alto de uma } \\
\text { árvore. }\end{array}$ \\
\hline Mito Banawa & $\begin{array}{l}\text { Uma mãe } \\
(\triangle, \text { adoção) }\end{array}$ & $\begin{array}{l}\text { não consegue } \\
\text { engravidar }\end{array}$ & $\begin{array}{l}\text { protetora por } \\
\text { via adotiva }\end{array}$ & $\begin{array}{l}\text { de um filho que } \\
\text { nasce dentro do } \\
\text { fruto de uma árvore. }\end{array}$ \\
\hline $\begin{array}{l}\text { Mito Pau- } \\
\text { mari }\end{array}$ & $\begin{array}{l}\text { Uma velha- } \\
\text { jaguar } \\
(\triangle, \text { adoção) }\end{array}$ & $\begin{array}{l}\text { adota sete filhos } \\
\text { (sete ovos de tarta- } \\
\text { ruga que viram as } \\
\text { Plểiades })\end{array}$ & $\begin{array}{l}\text { protetora por } \\
\text { via adotiva }\end{array}$ & $\begin{array}{l}\text { de um filho quado fog fobre o tron- } \\
\text { co de uma árvore. }\end{array}$ \\
\hline
\end{tabular}

6

\begin{tabular}{|c|c|c|c|c|}
\hline $\begin{array}{l}\text { [Chaco] Tendo em } \\
\text { vista uma busca } \\
\text { animal (pássaros) }\end{array}$ & $\begin{array}{l}\text { que a esposa } \\
\text { não deveria } \\
\text { comer (mas } \\
\text { come); }\end{array}$ & $\begin{array}{l}\text { disjunção } \\
\text { por causa do } \\
\text { marido }\end{array}$ & $\begin{array}{l}\text { Mãe morta por alia- } \\
\text { dos (= filhos, em } \\
\text { filiação pat.) }\end{array}$ & \multirow{2}{*}{$\begin{array}{l}\text { vítima } \\
\text { incinerada, } \\
\text { origem do } \\
\text { tabaco }\end{array}$} \\
\hline $\begin{array}{l}\text { [Bororo] Tendo em } \\
\text { vista uma busca } \\
\text { vegetal (frutas) }\end{array}$ & $\begin{array}{l}\text { que a mãe deve- } \\
\text { ría comer (mas } \\
\text { não come); }\end{array}$ & $\begin{array}{l}\text { disjunção por } \\
\text { causa da mãe }\end{array}$ & $\begin{array}{l}\text { Filho morto por } \\
\text { parentes (= tios } \\
\text { maternos, em fil- } \\
\text { iação mat.) }\end{array}$ & \\
\hline $\begin{array}{l}\text { [Banawa] Tendo } \\
\text { em vista uma busca } \\
\text { vegetal (castanhas) }\end{array}$ & $\begin{array}{l}\text { que a mãe deve- } \\
\text { ría comer (mas } \\
\text { não come); }\end{array}$ & $\begin{array}{l}\text { disjunção } \\
\text { por causa da } \\
\text { (não) mater- } \\
\text { nidade }\end{array}$ & $\begin{array}{l}\text { Mãe atacada por } \\
\text { mulheres (da mes- } \\
\text { ma aldeia) }\end{array}$ & \multirow{2}{*}{$\begin{array}{l}\text { líquidos } \\
\text { "inférteis" } \\
\text { (urina, esper- } \\
\text { ma), origem } \\
\text { do tabaco }\end{array}$} \\
\hline $\begin{array}{l}\text { [Paumari] Tendo em } \\
\text { vista uma busca ani- } \\
\text { mal (caçada da qual } \\
\text { não participa) }\end{array}$ & $\begin{array}{l}\text { que o filho deve- } \\
\text { ria comer (mas } \\
\text { "come" as esposas } \\
\text { dos irmãos) }\end{array}$ & $\begin{array}{l}\text { disjunção por } \\
\text { causa das cun- } \\
\text { hadas }\end{array}$ & $\begin{array}{l}\text { Filho que engana e faz } \\
\text { sexo com as mulheres } \\
\text { (cunhadas) }\end{array}$ & \\
\hline
\end{tabular}


As semelhanças dos paradigmas são notórias: as relações destruidoras/ protetoras, a topologia das árvores (alto/dentro), a busca vegetal ou animal (ações de coleta de plantas ou de caça), o comportamento anticulinário e as disjunções operadas - duas características com absoluto destaque na mitologia do tabaco - e os movimentos predatórios em relação às mães/ filhos. Porém, a contraposição entre os mitos banawa e paumari e os mitos bororo e do Chaco a respeito da origem do tabaco estabelece um contraste clássico no panorama ameríndio: a origem queimada ${ }^{18}$ (e anticulinária) do tabaco, que emerge como transformação das cinzas de um predador (a mulher-jaguar no mito do Chaco, a cobra gerada pelo sangue da sucuri no ventre da mulher bororo); e a origem molhada do tabaco nos mitos arawa: o tabaco como transformação da urina (líquido infértil) da mulher banawa que não consegue engravidar; ou do esperma ${ }^{19}$ (líquido fértil, mas que não fecunda, uma vez que o protagonista é obrigado a masturbar-se) do jovem que faz sexo com as cunhadas, até ser censurado pelo irmão.

Em ambos os protagonistas observa-se a relação anticulinária característica do tabaco: a mulher banawa não come a castanha (fruto comestível, mas preservado por conter uma criança); o jovem paumari não acompanha os irmãos na procura de comida (pois não participa da caçada). Estas variações arawa, como transformações do mito do tabaco, conectam com o rondó mitológico lévistraussiano que enlaça os mitos da carne, do fogo e do tabaco, no qual "tudo se encaixa: a fumaça do tabaco engendra os porcos-do-mato, de onde vem a carne. Para assar carne, é preciso que um desaninhador de pássaros consiga o fogo de cozinha do jaguar; e finalmente, para se livrar do jaguar, é preciso que um outro desaninhador de pássaros queime seu cadáver numa fogueira, dando assim origem ao tabaco" (CC 134). As narrativas arawa apresentam, neste sentido, uma nova torção, pois manifestam uma mitologia "em chave de água" (CC 136) para um tabaco que é consumido cotidianamente "em chave de fogo" (MC 414), preparado além da cozinha, com folhas de tabaco secas, que são torradas no fogo doméstico e, depois da trituração, temperadas com as cinzas da casca do cupuí.

\section{Da perda do tabaco}

O mel, antítese paradigmática do tabaco no movimento "regressivo" verificado em Do mel às cinzas, protagoniza uma mitologia que narra a sua origem, mas que insiste talvez com maior ênfase na sua perda (MC 67, 110, 241). Os mitos arawa manifestam também este contraponto em relação ao tabaco. A oeste dos Banawa e dos Suruwaha, cujas narrativas destacaram a 
origem do tabaco, os Deni dos rios Xeruã e Cuniuá (tributários, respectivamente, dos rios Juruá e Purus), falantes de língua arawa, narram o mito do roubo do tabaco, ou seja, da perda que os banideni ${ }^{20}$ ("o coletivo dos animais/ presas") sofreram quando os humanos se apropriaram dessa planta.

\section{Ukekeni e o roubo do tabaco ${ }^{21}$}

Ukekeni foi caçar junto com os outros, levando as zarabatanas. Eles mataram passarinhos, fizeram um tapiri e fogo no mato e moquearam os passarinhos. Depois de cinco dias, eles viram macaco-prego, zogue-zogue, parauacu e moquearam todos. Depois foram caçar de novo. Ukekeni viu um caminho e disse: "Vamos visitar o pessoal!". Eles viram um roçado grande. Ele foi ao roçado e viu muitas plantas para fazer rapé [shina]. Roubou dez folhas e levou-as para os seus companheiros. Ele contou para eles: "Eu vi um roçado grande!". Era o roçado de todo tipo de macaco. O macaco-prego viu que alguém tinha roubado as suas folhas de rapé. Os outros falaram: "Não, não fomos nós que roubamos!". Os homens foram caçar de novo. Ukekeni ficou no tapiri com seus dois filhos para fazer paneiros para os passarinhos moqueados. O macaco-prego foi atrás de rastros para ver quem tinha levado as folhas de rapé. Ele foi e achou Ukekeni. Ukekeni escutou os macacos falando. Ele ficou escondido e calado. Os macacos-prego viram os passarinhos moqueados, macaco-prego, zogue-zogue, parauacu, todos moqueados. E falaram: "Os nossos parentes morreram. Por isso estão faltando três parentes nossos. Esse pessoal roubou as folhas de rapé". Eles estavam rindo, vendo os parentes macacos duros e moqueados no jirau. Depois cutucaram a barriga do macaco zogue-zogue e perguntaram: "Quem moqueou você?". "Foi Madibikavi". Mais na frente cutucaram o macaco-parauacu e perguntaram: "Quem moqueou você?". "Foi Hamashime". Mais na frente cutucaram o macaco-prego e perguntaram: "Quem moqueou você?". "Foi Ukekeni".

Os macacos foram embora para sua aldeia e disseram para os parentes: "De tarde, às seis horas, vamos voltar de novo e, quando a gente estiver bem perto, vocês se levantam e agarram Ukekeni, Madibikavi e Hamashime. Nós vamos matá-los com cacetes!". Ukekeni tinha escutado toda a conversa deles. O pessoal de Ukekeni chegou do mato. Ukekeni contou tudo para eles. Seus companheiros não acreditaram. Ukekeni pegou o macaco-prego que tinha matado e comeu a sua cabeça para que ele não se agarrasse no seu pescoço quando os outros chegassem. Às cinco horas Ukekeni procurou um buraco de uma árvore e se escondeu. Então às seis horas os macacos chegaram gritando. Os outros macacos que estavam moqueados no chão levantaram-se, agarraram-se no pescoço dos companheiros de Ukekeni. Os outros macacos mataram todos os homens. Só Ukekeni tinha conseguido se salvar porque havia fugido e se escondido no 
buraco de uma árvore. Os macacos moquearam os companheiros de Ukekeni, comeram e disseram: "Hum! Muito gostoso! Tem muita banha! Vamos matar Ukekeni também!" [...].

[Na sequência, os macacos pedem ao jacamim que capture Ukekeni, mas ele fracassa. Posteriormente, o mutum consegue manter Ukekeni preso no buraco da árvore, mas ele dorme, possibilitando a fuga de Ukekeni e seus netos, que voltam a viver em paz].

[...] Ukekeni morava sozinho com os seus netos. Ele criou os netos. Um dia, as crianças já eram adultas, Ukekeni matou um macaco e eles o comeram. Deitaram-se na rede, e o neto falou para Ukekeni: "Se eu tivesse uma zarabatana, eu teria matado um monte de macacos e nunca iria faltar comida". Ukekeni disse a seu neto: "Pode tirar um pedaço do meu cotovelo. Aqui tem veneno. Do meu braço pode tirar um osso, aí você tem uma flecha". Então Ukekeni derreteu o pedaço de seu cotovelo, fez o veneno e colocou na ponta da flecha. O neto de Ukekeni falou para ele: "Vovô, coloque fruta de sorva perto da aldeia dos macacos. Eu vou vingar a morte do meu pai!" [...]. Aí o neto de Ukekeni foi atrás de todo o mundo com a sua zarabatana. Primeiro, chegou o jacamim. O neto de Ukekeni matou todos os jacamins. Mais na frente chegaram os coatis. Ele matou todos os coatis também. Depois chegaram perto da árvore de sorva. A árvore estava cheia de macacos comendo frutas de sorva. Então ele pegou a zarabatana e matou todos os macacos. A preguiça agarrou-se nos filhotes dos macacos e ficou calada lá em cima. Quando caíram os últimos macacos, a preguiça pulou com os filhotes de macacos para uma árvore de açaí. ${ }^{22} \mathrm{~A}$ árvore quebrou. A preguiça e os filhotes caíram no chão. Os filhotes correram para todos os lugares. Depois disso, o neto de Ukekeni voltou para a aldeia dos macacos, ouviu vozes e pensou: "Agora eles viraram macacos mesmo". Então ele voltou para a casa do seu avô Ukekeni e falou para o seu avô: "Matei todos os macacos, e eles viraram macacos mesmo". Se não fosse Ukekeni, todo mundo teria virado bicho [bani].

Segundo a concepção deni, os humanos eram bani ("animais/presas") num tempo ancestral. Este mito "apresenta os eventos que geraram uma fratura no cosmos, separando madi [humanos] e bani [animais] no nível ontológico" (Florido 2013:155). O que está em pauta é um conflito de perspectivas, que produz alterações nas posições de predador e de presa. Para os Deni, os humanos eram originariamente bani de alguns animais, e os próprios humanos caçavam e mantinham relações de predação com outros animais, o que indica que a posição bani era instável. Em um primeiro momento, o tabaco - roubado do roçado do macaco-prego - permite a Ukekeni sair da posição de presa e escapar do alcance dos seus predadores 
(os macacos que conseguem caçar o resto dos humanos). Em um segundo momento, o curare gerado do cotovelo de Ukekeni ${ }^{23}$ consolida os humanos (nos netos de Ukekeni) na posição de predadores. Os venenos - o tabaco, o curare - fixam os animais na posição de bani enquanto presas e garantem, portanto, a posição dos humanos enquanto caçadores - portanto, predadores.

Em outro relato dos Deni do rio Xeruã, o ancestral Kapihava recebe ameaças consecutivas de diversas pessoas: do jacaré, do veado, da anta e do tatu-canastra. Prepara o tabaco em forma de rapé forte e o oferece aos seus predadores, que vão sucessivamente transformando-se nas respectivas espécies animais. Atente-se ao desfecho desta narrativa:

Kapihava ficou sozinho e voltou para sua aldeia. Tinha ficado só um restinho de rapé para ele. Quando chegou à aldeia, pegou urucum, passou na perna e no bico e depois tomou rapé. Kapihava virou saracura. Antigamente o rapé era muito forte. Os Deni chamavam aquele rapé darisi, que fazia as pessoas virarem bicho mesmo. Hoje os Deni chamam o rapé de shina, que é feito de tabaco (Sass 2004:135-136). ${ }^{24}$

\section{De volta à etnografia}

Após este percurso pela mitologia, retomemos a abordagem etnográfica, dirigindo o olhar para a relação entre o tabaco e a caça. Em diversas expedições de caça das quais participei junto aos Deni da aldeia Cidadezinha, no rio Cuniuá, percebi o quanto o tabaco é indispensável para o seu sucesso. Em alguns momentos do percurso, o caçador inala intensamente o tabaco, esfrega a mão nos olhos cheios de lágrimas pelo efeito do rapé, e com o desenho dos restos de tabaco umedecidos na palma da mão "enxerga" o rumo oportuno ${ }^{25}$ e a espécie que poderá ser caçada. O tabaco, também nas práticas venatórias, aponta na direção dos animais na sua condição de presas, vítimas na caça.

No ritual de iniciação feminino entre os Jarawara, de acordo com a etnografia de Maizza (2012), o açoitamento da jovem iniciada pelos homens-queixadas implica uma transformação da mulher em queixada. Porém, "depois de chicotearem, o pai da menina sopra rapé nos homens e as mulheres os queimam, ${ }^{26}$ provavelmente para que eles deixem de ser queixadas e voltem a ser humanos" (Maizza 2012:223). Podemos pensar também que a ação de tabaco permite manter sob controle a "posição-queixada" (agressiva) dos homens, fixando os queixadas na posição de presas. Na etnografia do ritual de iniciação feminino do amamajo entre os Paumari, Bonilla (2007:235) 
descreve o momento em que os xamãs anunciam a chegada dos espíritos do beija-flor e do pica-pau, os quais introduzem na jovem mulher as substâncias que compõem o tabaco cerimonial (a mistura do tabaco hajiri com a resina de jatobá ijori). Os cantos dos xamãs acompanham a introdução da resina de jatobá no corpo da jovem e descrevem como os pássaros defecam na cabeça e nos ombros dela. As doses intensas de tabaco e os alucinógenos ${ }^{27}$ inalados provocam um estado de embriaguez, que torna a jovem apta para sair da reclusão ritual. Bonilla identifica semelhanças expressivas com o ritual kulina tocorimecca ajie descrito por Lorrain (1994), durante o qual os espíritos auxiliares dos xamãs introduzem frutas contraceptivas no abdome das mulheres e realizam curas mediadas pelo tabaco. "É em tais rituais xamânicos que varas de queixadas ou espíritos dos mortos são chamados pelos xamãs para serem caçados e comidos por seus parentes" (Lorrain 1994:79).

Já tínhamos observado a função disjuntiva do tabaco (MC 360, 400, além de CC 129) como separador de humanos e animais. As Mitológicas constatam isso em outros cenários etnográficos, como nos Irantxe de Mato Grosso (M191, "versão obscura e elíptica" em MC 54). No mito irantxe o herói humano protagonista, perseguido por um inimigo, é socorrido pelo urubu, que lhe oferece tabaco bom para fumar e tabaco ruim como instrumento de vingança. O herói oferece tabaco tóxico ao seu perseguidor humano: ele é transformado em tamanduá, o qual o protagonista caça; o cadáver decomposto da vítima é devorado pelo urubu, dono do tabaco. Mas permaneçamos no circuito mitológico dos Arawa. Num episódio do já referido mito paumari de Kahaso, o tabaco intervém no estabelecimento dos animais como presas dos humanos:

Os irmãos [de Kahaso] saíram ao encontro de um velho chamado Jacundá (peixe coberto de dardos). Ele era o dono das flechas, mas se recusou a dar-lhes. Então, à noite, os sete irmãos ofereceram-lhe rapé, muito forte, para drogá-lo. Assim que ele dormiu, fizeram voar as flechas e as distribuíram por todas as nações. Eles queriam também vingar-se do jaguar, mas outros animais atravessaram o caminho deles: os veados, os queixadas e os quatipurus: todas as presas que nós caçamos hoje (Bonilla 2007:39).

O tabaco, na concepção dos Arawa, realiza efetivamente a metamorfose "regressiva" das pessoas em animais, ou seja, transforma a posição do outro em uma posição de presa e constitui os humanos na condição de predadores dos animais. 


\section{A lógica reversa do tabaco e dos venenos}

Controvertidamente percebido como alimento ou como antialimento na mitologia ameríndia, Lévi-Strauss situa o tabaco "nos entornos da cozinha" (MC 442), já que precisa ser queimado para ser consumido ${ }^{28}$ - portanto, mais do que cozido e, em consequência, situado "além da cozinha". Assim como o mel e o timbó, o tabaco realiza "[a] passagem quase insensível da categoria do delicioso à do venenoso" $(M C 52,59)$. Ao mesmo tempo em que, em determinados contextos, pode ser classificado como alimento (e convive com as plantas comestíveis na roça), seus efeitos eméticos, entorpecentes e tóxicos permitem inscrevê-lo na ordem dos antialimentos - já foi observada no início deste artigo a peculiar condição de ambiguidade que o tabaco tem. Há inclusive uma relação lógica do tabaco com o sangue menstrual e com os excrementos (MC 360), de maneira que "o caminho do tabaco passa pela sujeira" (MC 400). Assim o comprovamos no mito banawa, ${ }^{29}$ em que o tabaco procede da transformação da urina de uma mulher infértil, ou nos cantos xamânicos paumari, que descrevem a defecação do beija-flor e do pica-pau sobre a jovem embriagada pelo tabaco cerimonial, quando terminam os ritos de reclusão.

O tabaco não é apenas alimento dos humanos, mas também dos espíritos. Lorrain (1994:79) afirma que, para os Kulina, os espíritos comem rapé, e no ritual do tocorimecca ajie, choram de desejo pelo tabaco e pelos cantos xamânicos das mulheres. Para os Paumari, o tabaco se alia a espíritos "contrapredadores" que exercem a devoração sobre as doenças, tornando-se protetores dos humanos: a garça-noturna anuncia a chegada das doenças infecciosas como o sarampo; para proteger-se, é necessário pegar dentes de piranha e recobri-los de tabaco, de forma que o espírito da piranha, fortalecido com a planta, devore a doença (Bonilla 2007:75).

Este caráter protetor do tabaco se observa entre os Kanamari, ${ }_{1}^{30}$ que habitualmente o consomem fora da aldeia "para ficarem cuidadosos" (tohia-dak). O tabaco é simultaneamente alimento do xamã e alimento do feitiço dyohko:

É com rapé que o xamã alimenta o dyohko que mantém guardado em sua bolsa, e ele próprio tem que se alimentar com rapé para ativar seu próprio $d y o h k o$ - para extrair (ou, no caso dos feiticeiros, introduzir) objetos patogênicos dos pacientes e também para possibilitar o ritual kohana (Costa 2007:265).

O mito kanamari que narra o tempo da separação entre tukuna e bara (respectivamente, "gente" e "caça") apresenta o conflito nas relações entre Paca, Veado e Anta. Anta desenvolve uma conduta predadora: mata e come 
o filho de Paca, e oferece a este uma porção do corpo do filho morto, como se fosse carne de caça. Quando Paca percebe a morte do seu filho, rouba o tabaco do roçado do Veado (que é o dono desta planta) e prepara o rapé que, misturado com o veneno do sapo wakoro (Phyllomedusa sp.), faz com que Anta vomite o filho de Paca que ele tinha devorado. Note-se como o tabaco, que tem uma posição "próxima aos alimentos" (pois é cultivado no roçado) se transforma, associado ao veneno, em antialimento para o predador. Paca e Veado enviam as cobras contra Anta, e neste ataque (que podemos novamente considerar como 'contrapredador') aliam-se às lacraias, às vespas e às arraias (todos eles notoriamente predadores) para provocar a morte de Anta e de sua filha. Por causa disso, "as antas ficaram furiosas e decidiram virar caça" (Costa 2007:239-241). Tanto os mitos kanamari quanto os arawa insistem nesta cisão transformacional entre os humanos e os animais/presas mediada pela planta do tabaco.

\section{Conclusão}

Fechemos o itinerário pelo pensamento arawa sobre o tabaco retornando aos Suruwaha. Um mito protagonizado pelo xamã dos Amaxidawa ${ }^{31}$ apresenta o poder que o tabaco e outros venenos têm (o timbó, o tinguí, o curare das flechas) para enfrentar a ação predatória dos estrangeiros canibais. Como foi possível perceber no mito kanamari, o tabaco e os demais venenos estabelecem a alteração entre as posições de vítima e de predador. A índole alimentar ou antialimentar do tabaco adquire, portanto, um caráter perspectivo, operando como disjuntor entre o ponto de vista humano (jadawa) e o ponto de vista canibal, não humano (jadawasu). O movimento antialimentar do tabaco e dos venenos é letal para os estrangeiros, mas se torna benéfico para os humanos.

\section{O tabaco e os venenos do xamã $\mathrm{Amaxi}^{32}$}

Os Amaxidawa moravam acima da foz do igarapé Muzahaha, nas nascentes do Riozinho. Um dia, um jovem amaxidawa foi caçar macacos-barrigudos. No local onde os estava perseguindo, chegaram os Jakimiadi e assopraram nele um feitiço sonífero. Caiu adormecido. Os Jakimiadi o pegaram, o levaram à sua casa perto do rio Waha; lá o puseram dentro de uma grande panela, foi cozinhado e comido por eles. O pai do jovem sentiu sua falta, foi buscar seu filho e encontrou o local onde ele tinha perseguido os macacos. Percebeu que seu filho tinha sido raptado pelos Jakimiadi. Ficou muito triste e chorou, chorou muito. Durante uns tempos, os Jakimiadi iam aos arredores da casa dos Amaxidawa. 
À noite, sempre que alguém saía para urinar, era raptado, conduzido a casa no rio Waha e comido pelos Jakimiadi. Desta maneira os Amaxidawa foram desaparecendo, um por um. Raptaram a esposa do xamã, raptaram todos os Amaxidawa, até que, finalmente, restou somente o xamã amaxidawa na sua casa. Ele olhava para as redes vazias, sentiu solidão e chorou muito com saudade da sua esposa e do seu povo. O xamã amaxidawa cheirou tabaco, cheirou muito tabaco, e se apropriou da força de todos os venenos: tomou a força do kaiximiani, tomou a força do xihixihi, ${ }^{33}$ tomou a força do timbó e a força do tinguí. Ficou muito gordo. Chegou o dia em que os Jakimiadi raptaram também o xamã dos Amaxidawa e o levaram para a sua casa. Queimaram seu cabelo, sua barba, suas axilas, os pelos do púbis, o cortaram e o cozinharam. Um Jakimiadi velho comeu as vísceras e os pés do xamã. Os Jakimiadi comeram toda a carne do xamã. Porém, depois de uns instantes, todos começaram a sentir-se mal devido aos venenos do xamã amaxidawa. O xamã dançava e cantava no ventre dos Jakimiadi, estes começaram a correr agitados, enlouquecidos, de um lugar para outro. As crianças caíam desfalecidas e morriam. O ventre dos adultos se dilatava mais e mais, até estourar. Todos os Jakimiadi morreram por causa do feitiço do xamã amaxidawa. Assim foi a história dos Amaxidawa, e do fim dos Jakimiadi.

Podemos constatar, a partir desta narrativa, que o tabaco e os venenos operam uma lógica reversa, contrapredatória: transformam a devoração canibal dos inimigos em antidevoração que favorece os humanos, anteriormente na condição de presas. As plantas de poder que o xamã consome ${ }^{34}$ transformam os humanos em predadores dos seus predadores. Neste sentido, o "movimento horizontal" que observamos tanto nas narrativas arawa sobre a origem do tabaco quanto nas que relatam a sua perda/roubo (em que o tabaco impõe o intervalo diatônico, descontínuo, entre humanos e animais) contrasta com um "movimento vertical", segundo o qual, para reverter a descontinuidade radical que há entre os humanos Amaxidawa e os seus caçadores canibais Jakimiadi, o xamanismo impulsiona um movimento de extrema densidade cromática ${ }^{35}$ através dos venenos. Junto ao tabaco, está o curare das flechas, kaiximiani, o mesmo veneno que as serpentes que caminham pelo arco-íris possuem; ${ }^{36}$ e o timbó e o tinguí, os venenos piscicidas que oscilam entre o efeito das suas propriedades "naturais" e o controle "cultural" que os humanos exercem ao usá-los. ${ }^{37} \mathrm{O}$ cromatismo dos venenos do xamã explode a diferença diatônica entre presas e predadores, revertendo a ordem instável do cosmos. Há aqui uma conexão direta com outros cenários ameríndios, nos quais encontramos mitos que evocam a origem do tabaco a partir das cinzas do jaguar (MC 181). 
Nas Mitológicas, os venenos são oportunamente caracterizados como "alimentos incomestíveis" (CC 308), e assim foi possível observá-los na narrativa suruwaha do xamã Amaxi. Como substâncias conectoras com a esfera sobrenatural, o tabaco e os venenos possibilitam a socialidade com os espíritos, "seres supremamente incomestíveis" (Viveiros de Castro 2006:320). Por isso, é pertinente concluir que as concepções arawa sobre o tabaco verificam, para além dos eixos acima identificados, um "movimento transversal"38 que aponta a capacidade de alteração na comunicação entre os diferentes sujeitos do cosmos. O tabaco age, portanto, com força cosmopolítica - veiculando a insistência do cosmos na vida sociopolítica dos humanos (Stengers 2007). Ele é, assim, uma espécie de caleidoscópio que expande nos humanos uma visão multiversal, heterotópica. ${ }^{39} \mathrm{O}$ consumo inebriante desta planta dá lugar a metamorfoses e extrapolações: confere aos humanos uma percepção excessiva, e os coloca em estado de alto risco perante o comparecimento de alteridades radicais. Ao subverter os limites na relação com os extra-humanos, a visão embriagante torna instáveis as distâncias entre os mundos. Talvez seja plausível pensar que, quando os Suruwaha descrevem o estado de embriaguez causado pelo tabaco como "explosão do olhar", tentam expressar a convergência excessiva de alteridades que caracteriza a visão dos xamãs.

Recebido em 04 de julho de 2016

Aprovado em 23 de setembro de 2016

Miguel Aparicio é doutorando do Programa de Pós-Graduação em Antropologia Social no Museu Nacional, Universidade Federal do Rio de Janeiro, Rio de Janeiro/RJ, Brasil. Bolsista do CNPq. E-mail: <mgl.aparicio@gmail.com> 


\section{Notas}

* Agradecimentos: transmito a minha gratidão a Verónica Soledad Lema (Universidad Nacional de La Plata), Edson Matarezio Filho (Universidade de São Paulo) e Juliana Lins (Instituto Nacional de Pesquisas da Amazônia) pela leitura atenta e pelas contribuições ao presente artigo. Da mesma forma, aos participantes do GT "Sobre hacer y deshacer. Alimentos y venenos en Tierras Altas y Tierras Bajas", que coordenei junto com Francisco Pazzarelli na XI Reunião de Antropologia do Mercosul (Montevidéu, dezembro de 2015). Para a compreensão dos textos de Lévi-Strauss, foi imprescindível a contribuição das aulas sobre Leitura das Mitológicas que Eduardo Viveiros de Castro ministrou no Museu Nacional entre março e julho de 2015: a ele, o meu agradecimento.

1 Além do clássico estudo de Wilbert (1987), saliento aqui - em uma lista que é necessariamente incompleta - os trabalhos etnográficos de Galvão (1953), Viveiros de Castro (1986), Baer (1992), Echeverri (1993), Erikson (1996), Sztutman (2003), Fausto (2004), Lima (2005), Barcelos Neto (2008) e, mais recentemente, a coletânea organizada por Russell \& Rahman (2015).

2 Realizei trabalho de campo entre os Suruwaha entre 1995-2001 e em 2010, no âmbito de projetos indigenistas promovidos pelo Cimi (Conselho Indigenista Missionário) e a Opan (Operação Amazônia Nativa). A experiência vivida junto aos Suruwaha deu suporte à produção da minha dissertação de mestrado em antropologia social, posteriormente revisada e publicada (Aparicio 2015). Entre 1999-2001 tive também a oportunidade de conviver em várias temporadas de campo junto aos Deni do rio Cuniuá, durante a campanha de combate à madeira ilegal em terras indígenas do Purus e de autodemarcação da Terra Indígena Deni apoiada por Greenpeace International. Desde 2014 realizo trabalho de campo entre os Banawa, onde desenvolvo minha atual pesquisa de doutorado. Os três grupos - Suruwaha, Banawa e Deni - são vizinhos, geograficamente muito próximos: habitam a bacia dos rios Tapauá-Cuniuá, afluentes do Purus à margem esquerda, no que podemos considerar um hinterland na região interfluvial entre os rios Purus e Juruá.

3 Convencionalmente os Arawa foram considerados como uma subdivisão da família linguística Arawak: este foi o ponto de vista de Ehrenreich (1891), Rivet e Tastevin (1938), Métraux (1948) e Nimuendajú (1981). Pesquisas linguísticas posteriores foram mostrando progressivamente a independência das línguas arawa (Dixon 1995; Dixon \& Aikhenvald 1999; Fabre 2004), compondo uma família diferente da família Arawak.

4 Com especial atenção, as pesquisas de Bonilla (2007) sobre os Paumari, de Maizza (2012) sobre os Jarawara e de Florido (2013) sobre os Deni, entre outros. Ghillean T. Prance $(1972,1978,1997)$ realizou um estudo pioneiro sobre venenos e narcóticos dos Deni, Paumari, Jamamadi e Jarawara, com informações relevantes sobre o uso de tabaco nestes grupos. Recentemente, Mendes dos Santos e Soares (2015) publicaram um artigo sobre rapé e xamanismo no Médio Purus a partir de informações bibliográficas - os cronistas e as referidas etnografias. 
5 Usarei ao longo do artigo as seguintes abreviaturas para referir-me aos três primeiros volumes das Mitológicas de Lévi-Strauss: CC: O cru e o cozido; MC: Do mel às cinzas; OMM: A origem dos modos à mesa, seguindo a edição que consta nas referências finais.

6 Ao falar em "rede arawa", não pretendo delimitar uma província etnográfica nem permanecer circunscrito a uma fronteira linguística. Os Arawa constituem uma rede de relações orientada por uma peculiar sociocosmologia dos lugares, que conecta os "humanos verdadeiros" num emaranhado de coletivos (os dawa dos Suruwaha, os madiha dos Kulina, os deni dos Jamamadi ocidentais e Deni etc.); uma malha social vinculada por rios, igarapés e caminhos ao longo do interflúvio Purus-Juruá (Aparicio 2013). As conexões com os Kanamari e com os Katukina do Biá (com língua independente, não arawa) são também significativas, por estarem imbricados na rede de relações dos Arawa; por isso o diálogo com as etnografias de Costa (2007) e de Deturche (2009) torna-se também pertinente na compreensão desta rede. Por motivos de espaço, não considerarei aqui as referências sobre as concepções e as práticas em relação ao tabaco nos Apurinã (de língua arawak), também engajados nesta rede, e estudados por Schiel (2004), Gow (2015) e Virtanen (2015).

7 Gow (2015: 50) recorre a esta expressão lévistraussiana para expressar a sua hesitação em relação à distinção analítica entre os usos "recreativo" e "xamânico" do tabaco no contexto amazônico.

8 O tabaco suruwaha é da espécie Nicotiana tabacum L. O cupuí, cujas cinzas se misturam ao pó do tabaco, corresponde à espécie Theobroma subincanum. Na língua suruwaha, o termo kumadi designa tanto a planta do tabaco quanto a mistura de tabaco em pó e cinzas de cupuí pronta para ser inalada (o mesmo acontece com os termos sina e shina, respectivamente, nas línguas banawa e deni). É por isso que prefiro usar a expressão tabaco, e não "rapé", ao longo do texto. Além disso, a expressão "rapé" (procedente do francês râpé, "ralado") é inadequada para expressar a natureza "queimada" do tabaco suruwaha, como veremos a seguir. O termo suruwaha huku designa o cupuí, mas em diversos contextos pode ser também traduzido como "tempero".

9 No ritual do xingané dos Apurinã do Purus, há um encontro entre guerreiros anfitriões e visitantes em que se realiza uma troca de discursos cerimoniais (sãkire). As armas são apontadas respectivamente entre os dois grupos. "Quando abaixam a voz, abaixam também as armas e os líderes tomam rapé na mão um do outro" (Schiel 2004: 81).

10 O mesmo termo é usado, em língua suruwaha, para "assoprar tabaco" ( $k u$ madi ahutukwa) e para "disparar dardos da zarabatana" (kanixi ahutukwa).

11 Sobre o poder apaziguador do tabaco, cfr. Echeverri (1993).

12 Na sua etnografia dos Yudjá, Lima também identifica a "função visual do tabaco", em que o êxtase produzido pelo tabaco torna a noite clara como o dia para os xamãs (2005:254). Mais informações sobre os espíritos-cantores kurimia em Aparicio (2015:124-130). 
13 Os três povos são falantes de línguas arawa e habitam a mesma bacia dos rios Tapauá-Cuniuá, importante afluente do rio Purus na margem ocidental e um dos principais eixos de circulação no interflúvio Purus-Juruá.

14 Este mito me foi narrado por Inácio, banawa da aldeia Paraíba, em abril de 2014. Inácio relatou o mito em português, e houve intervenções em língua banawa da sua esposa, Damani. A transcrição a posteriori é minha.

15 Extraído de Bonilla (2007:39) (tradução minha da versão em francês da autora). O episódio de Kahaso e a origem do tabaco faz parte de uma grande narrativa paumari sobre "o tempo dos antigos", protagonizada pelos heróis ancestrais Jamapitoari, Jakoniro e Kahaso. Segundo o mito, do ventre de Jakoniro saíram sete ovos de tartaruga que se transformaram em ovos de bem-te-vi. Uma velha-jaguar fez deles seus animais familiares, que se transformaram nas Plêiades. Kahaso é o mais novo dos sete irmãos. O mito descreve Kahaso (literalmente, "pele áspera, rugosa") como uma pessoa pequena, feia e com a pela coberta de feridas, mas detentor de um intenso poder xamânico.

16 Lévi-Strauss recorreu à "teoria dos grupos" do matemático F. Klein para analisar a estrutura dos mitos em forma de analogia; os elementos do mito são considerados nas suas propriedades relacionais, e sua descrição consiste em analisar as suas simetrias como grupos de transformações. O grupo de Klein é um conceito topológico que permite expressar uma lógica de relações de oposição entre códigos paradigmáticos diferentes, e a transformação de uma relação metonímica em uma relação metafórica, o que possibilita, por exemplo, evidenciar a dinâmica de transformação entre forma e conteúdo. A este respeito, cfr. Almeida (1999, 2008) e Mendes (2014).

17 As duas primeiras filas do quadro, que fazem referência aos mitos do Chaco e bororo (destacadas em cinza) foram literalmente extraídas de CC 132-37. Acrescentei a terceira e quarta filas, respectivamente sobre os mitos banawa e paumari, para evidenciar as conexões paradigmáticas entre as quatro versões.

18 O tabaco queimado apresenta uma oscilação que o situa na direção do "polo narcótico" do tabaco, em contraposição ao tabaco molhado, mais próximo do mel. Com frequência, ambas as dimensões se confundem ou se compenetram, por isso "é de esperar que as relações de transformação entre os diversos tipos de mitos 'de mel' e 'de tabaco' assumam o aspecto de um quiasma" (MC 62).

19 Há também nas Mitológicas uma relação entre o esperma e o sangue menstrual, que aparece no mito terena contemplado (M24) e, ainda, do esperma com o mel: "O esperma é o que deve passar do marido à mulher, e o sangue menstrual, $o$ que não deve passar da mulher para o marido. Ora, mostramos em Do mel às cinzas que o mel é o que deve passar do marido para os pais da mulher, indo, portanto, no mesmo sentido que o esperma, mas mais adiante" (OMM 371, nota 9). Na concepção dos Yawalapíti, Viveiros de Castro identifica o tabaco como alimento propriamente xamânico, "o equivalente e a contrapartida espiritual do esperma. Se o segundo fabrica os indivíduos, o primeiro os recria" (2002:59). 
20 Nas línguas arawa, o termo bani (bahi em Suruwaha) aponta uma condição geral de "animal na condição de presa", com algumas especificidades em cada grupo. Nos Kulina, segundo Pollock (1985), bani significa "carne", e é o alimento por excelência; contudo, os animais familiarizados no espaço doméstico são denominados odza bani. Nos Jarawara, "bani quer dizer literalmente caça, podendo significar também animal em geral, sem especificar qual. Mas não seria qualquer animal e sim um animal considerado boa caça" (Maizza 2012: 48). Nos Jamamadi orientais, R. Campbell e B. Campbell traduzem bani como "animal de caça, carne (especialmente queixada)". Nos Suruwaha, bahi significa "presa, vítima", e se aplica tanto aos animais caçados quanto aos humanos submetidos à ação de predadores: juma bahi ("presas dos [inimigos] juma"), mazaru bahini ("vítimas do feitiço"), kunaha bahi ("presas do timbó") etc. Para os Banawa do rio Piranhas, bani aponta também a condição de presa que os animais possuem em relação aos humanos. Nos Deni, bani se refere aos animais de caça, num sentido mais geral de presa, objeto de predação violenta, mas há usos que de alguma forma apagam o contraste presa/ predador, visto que, "diferente dos Jarawara, bani não corresponde apenas à posição de presa, pois os Deni atribuem para a onça o nome bani zavirivi ("bani malhado"), que seria utilizado antigamente, ou seja, quando as onças ainda eram predadores de humanos" (Florido 2013:155-156).

21 Esta versão foi registrada por Sass (2004:62-67) entre os Deni do rio Xeruã. Há também uma versão registrada por Florido (2013:156-158) entre os Deni do rio Cuniuá. Na versão do rio Cuniuá, o protagonista é Kapihava, irmão de Ukekeni na mitologia deni.

22 Na versão do rio Cuniuá, estes filhotes que a preguiça salva são filhotes de macaco-coatá, macaco-barrigudo, macaco-parauacu e macaco-prego.

23 Para os Suruwaha, o cotovelo é fonte de perigo, de maneira que um golpe de cotovelo no corpo de outra pessoa (voluntariamente ou não) produz a transmissão do feitiço, mazaru.

24 Nas narrativas dos Deni do rio Cuniuá, Kapihava experimentou o curare que tinha preparado atirando com a zarabatana no uirapuru (maphi) e no beija-flor (duphiphi). "Como ele conseguiu matar estes dois passarinhos, Kapihava e os seus se transformaram em animais, mas se ele tivesse errado, seríamos nós que teríamos nos transformado em caça", explica o narrador deni (Florido 2013:158). É interessante o comentário de Florido sobre este episódio: "Kapihava caçou a caça que os humanos não caçam. Matou os passarinhos que os humanos não conseguem matar com a zarabatana. Pecou por excesso, ao ser habilidoso demais com a zarabatana" (comunicação pessoal).

25 Conexões estreitas entre tabaco e caça são estabelecidas também pelos Uitoto, na Amazônia colombiana (Echeverri 1993). Para os Araweté do Xingu, o tabaco é um "mostra-caminho" (Viveiros de Castro 1986:534, nota 51), mas há uma diferença entre a lógica vertical do tabaco araweté (orientado aos espíritos) e a lógica horizontal do tabaco deni (orientado aos animais). 
26 No ritual, as mulheres jarawara queimam os homens com brasas de um tipo de embira acesa ou com breu (Fabiana Maizza, comunicação pessoal).

27 As plantas alucinógenas misturadas ao tabaco cerimonial dos Paumari são: koribo-nafoni (Tanaecium nocturnum), kavabo (Virola elongata) e manaka (não identificada). Cfr. Bonilla (2007:179) e Prance et al. (1977).

28 Em relação às modalidades de consumo de tabaco na América do Sul, é imprescindível reportar-se ao exaustivo estudo comparativo de Wilbert (1987). É também interessante a síntese panorâmica (distribuição do consumo, modalidades de uso, utensílios vinculados) realizada por Cooper (1997:111-134). Em um texto recentemente publicado, Peter Gow propõe um estudo na forma de "comparação controlada" sobre os instrumentos utilizados no consumo do tabaco entre os Piro e os Apurinã. O autor observa uma progressão lógica das formas plásticas nestes instrumentos, e identifica um grupo transformacional, segundo as dinâmicas da análise estrutural lévistraussiana. Para Gow (2015:60), "métodos de uso do tabaco, instrumentos do uso do tabaco e órgãos do uso do tabaco, provavelmente com origens históricas muito díspares, estão constantemente sendo elaborados em sistemas estruturais locais específicos que estão sempre cientes dos sistemas vizinhos e procurando estabelecer mediações transformacionais entre os sistemas, tanto interna quanto externamente".

29 O mito banawa da origem do tabaco, em que a urina da mulher protagonista vai espalhando plantas de tabaco, encontra ressonâncias no mito tikuna de origem do timbó, em que uma mulher virgem engravida ao sentar-se sobre uma planta de timbó. Dessa gravidez nasce um filho venenoso ao extremo. Na narrativa tikuna o filho do timbó vai espalhando veneno pelo mundo: "Onde ele cuspia (fai), onde ele defecava (woeün), onde ele urinava (wiya), nascia um filhinho dele, um cipó timbó. Ele andou pelo mundo inteiro e espalhou a planta do timbó por todos os lugares onde passou" (Matarezio Filho 2015:248).

30 Como já observei, os Kanamari não fazem parte da família linguística Arawa, mas sim da sua rede de relações. As conexões mitológicas são estreitas, e precisam ser contempladas. Para uma leitura completa do mito kanamari que sintetizo em seguida, cfr. Costa (2007:239-241).

31 Antepassados dos Suruwaha, que protagonizam diversas narrativas contemporâneas.

32 Narrado por Kwakwai durante uma caçada no igarapé Muzahaha em outubro de 1997 (a tradução para o português é minha).

33 Kaiximiani e xihixihi são os dois compostos com os quais os Suruwaha elaboram o veneno das flechas. Não consegui identificar as espécies vegetais usadas por eles na composição do curare, mas é muito provável que se trate das plantas utilizadas pelos vizinhos Jamamadi e Jarawara, identificadas por Prance $(1972,1997)$.

34 O consumo excessivo de tabaco e venenos como maneira de potencializar a capacidade xamânica aparece, por exemplo, na concepção dos Matsigenka, que denominam os xamãs como "aqueles intoxicados pelo tabaco" (Baer 1992:79). 
35 Ao longo das Mitológicas, Lévi-Strauss observa uma tensão entre os pequenos e grandes intervalos: o cromático faz referência às contiguidades, o diatônico às descontinuidades diferenciadoras. "Embora Lévi-Strauss enfatize que a intenção última do pensamento estaria ligada ao estabelecimento dos grandes intervalos e das oposições mais fundamentais, isto é, ao modo diatônico, reconhece que o cromatismo é recorrente no pensamento ameríndio" (Gonçalves 2007:147).

36 O arco-íris, cujo poder letal é reconhecido pelos ameríndios (conforme constata Lévi-Strauss em MC 73), é para os Suruwaha kuwiri agi, o caminho dos mortos atacados pelas cobras. "Os mitos sul-americanos situam o arco-íris, ou a cobra arco-íris, na origem do veneno de pesca e das epidemias, devido ao caráter maléfico que o pensamento indígena atribui ao cromatismo, tomado no sentido de reino dos pequenos intervalos" (MC 267).

37 Para Lévi-Strauss, o cromatismo dos venenos de pesca opera um curto-circuito segundo o qual "a natureza e a animalidade se invertem em cultura e humanidade" (CC 316). Parece uma chave análoga à que articula o mito suruwaha, em que os venenos produzem a inversão de posições que transforma os não humanos jadawasu em vítimas e que restabelece a vida dos humanos jadawa.

38 No sentido indicado por Viveiros de Castro, para quem o conceito de transversalidade "designa um modo de comunicação entre heterogêneos característico das multiplicidades intensivas ou rizomáticas, [...] sugerindo uma linha de fuga" (2008:80) em relação às coordenadas 'horizontal' e 'vertical' do xamanismo identificadas na análise de Hugh-Jones (1996).

39 As heterotopias, segundo Foucault (1984), fazem referência a lugares de diferença plena, diversos das utopias porque expressam mundos reais: são constitutivamente outros. Um dos atributos das heterotopias é a sua capacidade de conectar lugares incompatíveis - neste sentido, o conceito parece-me perfeitamente adequado para caracterizar a condição xamânica. 
Referências bibliográficas

ALMEIDA, Mauro. 1999. "Simetria e entropia: sobre a noção de estrutura de Lévi-Strauss". Revista de Antropologia, 42(1-2):163-197.

2008 "A fórmula canônica do mito". In: Rubem C. Queiroz \& Renarde F. Nobre (orgs.), Lévi-Strauss. Leituras brasileiras. Belo Horizonte: Ed. UFMG. pp. 147-182.

APARICIO, Miguel. 2013. "Os Suruwaha e sua rede de relações. Uma hipótese sobre localidades e coletivos Arawa". In: Marta Amoroso \& Gilton Mendes dos Santos (orgs.), Paisagens ameríndias: lugares, circuitos e modos de vida na Amazônia. São Paulo: Editora Terceiro Nome. pp. 247-273. . 2015. Presas del veneno. Cosmopolítica y transformaciones suruwaha (Amazonía occidental). Quito: Editorial Universitaria Abya Yala.

BAER, Gerhard. 1992. "The one intoxicated by tobacco: Matsigenka shamanism". In: E. J. Langdon \& G. Baer (eds.), Portals of power: shamanism in South America. Albuquerque: University of New Mexico Press. pp. 79-102.

BARCELOS NETO, Aristóteles. 2008. Apapaatai. Rituais de máscaras no Alto Xingu. São Paulo: Edusp.

BONILLA, L. Oiara. 2007. Des proies si désirables: soumisson et prédation pour les Paumari d'Amazonie brésilienne. Tese de Doutorado em Antropologia Social, École des Hautes Études en Sciences Sociales, Paris, França.

CAMPBELL, Robert \& CAMPBELL, Barbara. 1992. Jamamadi dictionary. Dallas, Texas: Summer Institute of Linguistics.
COOPER, John M. 1997. "Estimulantes e narcóticos". In: B. Ribeiro (ed.), Suma etnológica brasileira 1. Etnobiologia (Edição atualizada do Handbook of South American Indians). Belém: Editora Universitária UFPA. pp. 111-134.

COSTA, Luiz A. 2007. As faces do jaguar. Parentesco, história e mitologia entre os Kanamari da Amazônia Ocidental. Tese de Doutorado em Antropologia Social, Programa de Pós-Graduação em Antropologia Social, Museu Nacional, Universidade Federal do Rio de Janeiro.

DETURCHE, Jérémy. 2009. Les Katukina du Rio Biá (Etat d'Amazonas, Brésil). Histoire, organisation sociale et cosmologie. Tese de Doutorado, Université de Paris Ouest, Paris, Nanterre, França.

DIXON, R.M.W. 1995. "Fusional development of gender marking in Jarawara possessed nouns". International Journal of American Linguistics, 61(3): 263-294.

DIXON, R.M.W. \& AIKHENVALD, A.Y. (eds.). 1999. The Amazonian languages. Cambridge/ New York/ Melbourne: Cambridge University Press.

ECHEVERRI, J. Álvaro. 1993. Tabaco frío, coca dulce. Palabras del anciano Kinerai de la Tribu Cananguchal para sanar y alegrar el corazón de sus huérfanos. Bogotá: Concultura.

EHRENREICH, P. 1948 [1891]. "Contribuições para a etnologia do Brasil. Parte 2: Sobre alguns povos do Purus". Revista do Museu Paulista, 2:17-135.

ERIKSON, Philippe. 1996. La griffe des aïeux: marquage du corps et démarquages ethniques chez les Matis d'Amazonie. Paris: Peeters Publishers. 
FABRE, A. 2004. "Arawa". In: Diccionario etnolinguístico y guía bibliográfica de los pueblos indígenas sudamericanos. Disponível em: http://butler. cc.tut.fi/ fabre/BookInternetVersio $/$ Dic $=$ Araw\%E1.pdf. Acesso em 18/10/2006.

FANK, Jonia \& PORTA, Edineia. 1996. Mitos e histórias dos Sorowaha. Cuiabá: Opan/Cimi.

FAUSTO, Carlos. 2004. "A blend of blood and tobacco: shamans and jaguars among the Parakanã of Eastern Amazonia". In: Neil Whitehead \& Robin Wright (eds.), In darkness and secrecy. The anthropology of assault sorcery and witchcraft in Amazonia. Durhan: Duke University Press. pp. 157-178.

FLORIDO. Marcelo. 2013. Os Deni do Cuniuá: um estudo do parentesco. Tese de Doutorado em Antropologia Social, Programa de Pós-graduação em Antropologia Social, Universidade de São Paulo.

FOUCAULT, Michel. 1984. "Dits et écrits. Des espaces autres (conférence au Cercle d'études architecturales, 14 mars 1967)". Architecture, Mouvement, Continuité, 5:46-49.

GALVÃO, Eduardo. 1953. "Cultura e sistema de parentesco das tribos do Alto Xingu". Boletim do Museu Nacional, (14):56.

GONÇALVES, Marco Antônio. 2007. "Do cromático ao diatônico: as Mitológicas e o pensamento ameríndio". Revista Brasileira de Ciências Sociais, 22(65):147-149.

GOW, Peter. 2015. "Methods of tobacco use among two Arawakan-speaking peoples in Southwestern Amazonia: a case study of structural diffusion". In: A. Russel \& E. Rahman (orgs.), The master plant. Tobacco in Lowland South America. London: Bloomsbury. pp. $45-63$
HUGH-JONES, Stephen. 1996. "Shamans, prophets, priests and pastors". In: Nicholas Thomas \& Caroline Humphrey (orgs.), Shamanism, history, and the State. Ann Arbor: University of Michigan Press. pp. 32-75. LÉVI-STRAUSS, Claude. 2004 [1964]. O cru e o cozido (Mitológicas 1). São Paulo: Cosac Naify.

2004 [1967]. Do mel às cinzas (Mitológicas 2). São Paulo: Cosac Naify. 2006 [1968]. A origem dos modos à mesa (Mitológicas 3). São Paulo: Cosac Naify.

LIMA, Tania Stolze. 2005. Um peixe olhou para mim. O povo Yudjá e a perspectiva. São Paulo: Unesp/ISA/ NuTI.

LORRAIN, Claire. 1994. Making ancestors. The symbolism, economics and politics of gender among the Kulina of Southwest Amazonia (Brazil). Tese de Doutorado, King's College, Cambridge, Inglaterra.

MAIZZA, Fabiana. 2012. Cosmografia de um mundo perigoso. Espaço e relações de afinidade entre os Jarawara da Amazônia. São Paulo: Nankin Editorial/Edusp.

MATAREZIO FILHO, Edson T. 2015. A festa da moça nova. Ritual de iniciação feminina dos índios Ticuna. Tese de Doutorado em Antropologia Social, Programa de Pós-graduação em Antropologia Social, Universidade de São Paulo.

MENDES, Tássia N. 2014. Lévi-Strauss e a tríade da estrutura: a linguagem, o simbólico e o inconsciente. Dissertação de Mestrado em Filosofia, Programa de Pós-graduação em Filosofia, Universidade Federal de São Carlos.

MENDES DOS SANTOS, Gilton \& SOARES, Guilherme H. 2015. "Rapé e xamanismo entre grupos indígenas no Médio Purus, Amazonas". Amazônica: Revista de Antropologia, 7:10-27. 
MÉTRAUX, A. 1948. "Tribes of the Juruá-Purus basin". In: J. H. Steward, Handbook of South American Indians. Vol. 3 - The Tropical Forest Tribes. Washington: Smithsonian Institution. pp. 657-686.

NIMUENDAJÚ, Curt. 1981. Mapa etno-histórico. Rio de Janeiro: Instituto Brasileiro de Geografia e Estatística, 1981.

POLLOCK, Donald. 1985. Personhood and Illness among the Culina of Western Brazil. Tese de Doutorado em Antropologia. New York: The University of Rochester.

PRANCE, G. T. 1972. "Ethnobotanical notes from Amazonian Brazil". ECOnomic Botany, 26(3):221-237.

1978. "The poisons and narcotics of the Dení, Paumari, Jamamadí and Jarawara indians of the Purus river region". Revista Brasileira de Botânica, 1(1):71-82.

1997. "Etnobotânica de algumas tribus amazônicas". In: B. Ribeiro (ed.), Suma etnológica brasileira 1. Etnobiologia. $3^{a}$ ed. (Edição atualizada do Handbook of South American Indians). Belém: Editora Universitária UFPA. pp. 135-151.

PRANCE，G. T.; CAMPBELL， D. G. \& NELSON, B. W. 1977. "The ethnobotany of Paumari indians". Economic Botany, 31:119-175

RIVET, P. \& TASTEVIN, C. 1938. "Les langues arawak du Purus et du Juruá (groupe arauá)". Journal de la Société des Américanistes, 30(1):71-115.

RUSSELL, Andrew \& RAHMAN, Elizabeth (eds.). 2015. The master plant: tobacco in Lowland South America. London: Bloomsbury.

SASS, Walter (org.). 2004. Ima Bute Denikha. Mitos deni. São Leopoldo: Oikos-Comin.

. (org.). 2007. Tâkuna nawa bûh amteiyam amkira. Mitos kanamari. São Leopoldo: Oikos-Comin.
SCHIEL, Juliana. 2004. Tronco velho. Histórias apurinã. Tese de Doutorado, Programa de Pós-graduação em Antropologia Social, Unicamp, Campinas.

STENGERS, Isabelle. 2007. "La proposition cosmopolitique". In: J. Lolive \& O. Soubeyran O. (orgs.), L'émergence des cosmopolitiques. Paris: La Découverte. pp. 45-68.

SZTUTMAN, Renato. 2003. "Comunicações alteradas. Festa e xamanismo na Guiana". Campos. Revista de Antropologia Social, 4:29-51.

VIRTANEN, Pirjo K. 2015. "Fatal substances: Apurinã's dangers, movement and kinship". Indiana, 32:85-103.

VIVEIROS DE CASTRO, Eduardo. 1986. Araweté. Os deuses canibais. Rio de Janeiro: Jorge Zahar Editor/Anpocs. . 2002. "Esboço de cosmologia yawalapíti". In: A inconstância da alma selvagem e outros ensaios de antropologia. São Paulo: Cosac Naify. pp. 27-85.

. 2006. "A floresta de cristal. Notas sobre a ontologia dos espíritos amazônicos". Cadernos de Campo, 14/15:319-338. . 2008. "Xamanismo transversal. Lévi-Strauss e a cosmopolítica amazônica". In: R. C. Queiroz \& R. F. Nobre (orgs.), Lévi-Strauss. Leituras brasileiras. Belo Horizonte: Editora UFMG. pp. 79-124.

WILBERT, Johannes. 1987. Tobacco and shamanism in South America. New Haven/ London: Yale University Press. 


\section{A EXPLOSÃO DO OLHAR: DO TABACO NOS ARAWA DO RIO PURUS}

\section{Resumo}

Na mitologia arawa, o tabaco é concebido "em chave de água", enquanto a presença desta planta na vida cotidiana mostra, paradoxalmente, um movimento "em chave de fogo". O tabaco e os venenos revelam, para os grupos indígenas do Purus, um cromatismo genuíno, no marco da "mitologia regressiva" que Lévi-Strauss encontrou em outros contextos ameríndios. Nas narrativas arawa, o tabaco é percebido como alimento, mas os seus efeitos eméticos, entorpecentes ou tóxicos permitem situá-lo entre os antialimentos. Tabaco e venenos operam uma lógica reversa, que transforma as presas em predadores dos seus predadores. O xamanismo efetiva um movimento de aproximação perigosa com a alteridade através dos venenos, ao associar o tabaco ao curare das flechas, ao veneno das serpentes, ao timbó. Nos mitos arawa (Suruwaha, Banawa, Deni...), o cromatismo dos venenos do xamã transtorna a diferença entre presas e predadores, e reverte a ordem instável do cosmos.

Palavras-chave: Tabaco, Venenos, Arawa, Xamanismo, Mitologia.

\section{THE EXPLOSION OF THE GAZE: ON TOBACCO FOR THE ARAWA OF THE PURUS RIVER}

\begin{abstract}
In Arawan mythology, tobacco is conceived of "in an aquatic key", while the presence of this plant in everyday life paradoxically shows a movement "in a flaming key". For indigenous groups inhabiting the Purus river, tobacco and poisons, reveal a genuine chromaticism within the framework of the "regressive mythology" that Lévi-Strauss found in other Amerindian contexts. In Arawan narratives, tobacco is perceived as food, but its emetic, narcotic and toxic effects allow it to be considered an "antifood". Tobacco and poisons operate an inverse logic that turns prey into the predator of their predators. Shamanism enables a dangerous approach to alterity through poisons, by associating tobacco with the curare of arrows, the poison of snakes, and the fish poison timbó. In Arawan myths (Suruwaha, Banawa, Deni ...), the chromaticism of the shaman's poison upsets the difference between prey and predator, reversing the unstable order of the cosmos.
\end{abstract}

Key words: Tobacco, Poisons, Arawa, Shamanism, Mythology. 


\section{LA EXPLOSIÓN DE LA MIRADA: \\ DEL TABACO ENTRE LOS ARAWA DEL RÍO PURÚS}

\section{Resumen}

En la mitología arawa, se concibe el tabaco "en clave de agua", mientras que la presencia de esta planta en la vida cotidiana muestra, paradójicamente, un movimiento "en clave de fuego". El tabaco y los venenos revelan, para los grupos indígenas del Purús, un cromatismo genuino, en el marco de la "mitología regresiva" que Lévi-Strauss encontró en otros contextos amerindios. En las narrativas arawa, al tabaco se le considera como alimento, pero sus efectos eméticos, estupefacientes o tóxicos permiten situarlo entre los antialimentos. Tabaco y venenos operan bajo una lógica reversa, que transforma las presas en predadores de sus predadores. El chamanismo desarrolla un movimiento de aproximación peligrosa con la alteridad a través de los venenos, al asociar el tabaco al curare de las flechas, al veneno de las serpientes, al barbasco. En los mitos arawa (Suruwaha, Banawa, Deni...), el cromatismo de los venenos del chamán trastorna la diferencia entre presas y predadores, y subvierte el orden inestable del cosmos.

Palabras-clave: Tabaco, Venenos, Arawa, Chamanismo, Mitología. 